\title{
Translation Features of Chinese Version of Emily Dickinson's Poetry Selection Final Harvest
}

\author{
Jianxin Zhou \\ South China University of Technology, China \\ wo777277@sohu.com
}

DOI: $\underline{\text { http://doi.org/ 10.36892/ijlls.v3i2.560 }}$

\begin{tabular}{ll}
\hline $\begin{array}{l}\text { Received: } \\
\text { 19/04/2021 }\end{array}$ & Final Harvest(1996) is the first and only Chinese translation of Emily \\
& Dickinson's poetry selection of 576 poems, Final Harvest(1961). Using Antconc \\
Accepted: & software and program written in python language, a statistical analysis of \\
relevant data of stanzas, lines, punctuation marks, transliterated words and & conjunctions in translated version and original book is conducted, to reveal \\
& translation features of the translation. It is found that the translation deviates \\
\hline Keywords: & slightly from the original in terms of stanza, line and punctuation, yet there are \\
Emily Dickinson's & obvious deviations from the original in translation of transliterated words and \\
poetry, Chinese & conjunctions in that a large number of transliterated words are not annotated \\
version, Final & with footnotes or given explanation, and original logical relation displayed by \\
Harvest, translation & conjunctions are often distorted or missing in translation. In general, the \\
features & faithfulness of the translation to the original is mainly manifested in poetic form \\
& rather than in content.
\end{tabular}

\section{INTRODUCTION}

Emily Dickinson (1830-1886) is an outstanding American poetess of the 19th century. Together with Walt Whitman (1819-1892), she can be regarded as forerunner of modern American poetry $(\mathrm{Li}, 2018)$. Her poems rarely follow stereotyped rhyming pattern, and use half rhyme or no rhyme in her poems extensively which is a rare precedent in poetry writing at that time. It can be said that she was a unique one in that era (Feng, 2018). She expresses in her poems not only her light or strong emotion but also her wise thinking and unique insights on many topics such as life, religion, nature, death, and love. Dickinson is praised as a great and most creative poet and even the greatest female poet since Sappho (Yao, 2009).

However, such an important poet in American literary history is far less well-known in China than such English poets as George Gordon Byron(1788-1824) and Percy Bysshe Shelley (1792-1822), whose works have been extensively translated into Chinese and widely read by Chinese readers. Dickinson's writing is rebellious by nature, very neat and concise, frequently ungrammatical, which inevitably make her poems obscure and increase the difficulty of translating her poems $(\mathrm{He}, 2004)$. It can be said that her unique poetic style and obscure meaning are the main reasons why she is not as well known as Shelley and Byron in China. Even though there have been some Chinese translations of Emily Dickinson poems today in China, there are still very few scholars commenting on the translations and offering valuable suggestions on translation (Zhou, 2021).

Most of Dickinson's poems, basically without title, are discovered by her sister Lavinia Norcross Dickinson (1833-1899) after Dickinson's death in 1886 (Feng, 2018). Of the nearly 2,000 poems Dickinson wrote, only 10 were published during her lifetime, which were drastically revised by editors to fit traditional poetic rules, making her unique style completely 
unrecognizable. It was not until 1955 that The Poems of Emily Dickinson (Dickinson, 1955), edited by Thomas Herbert Johnson(1902-1985), was published, which contains 1775 complete poems and incomplete fragments, and even reproduces the traces of deliberation and alteration, therefore, readers of the world can finally read complete Dickinson's poems with nearly the original appearance (Liu, 2010). The reader edition, The Complete Poems of Emily Dickinson (Dickinson, 1960), also edited by Thomas H. Johnson, was published in 1960. Final Harvest: Emily Dickinson's Poems, edited by Johnson, was published in 1961 by Little, Brown and Company, a well-known American publishing house.

Final Harvest is the first selected volume of Dickinson's work that draws from all 1,775 of her poems. It is the only select volume of Emily Dickinson's poetry that truly represents the complete range of her work, and the richest and most authoritative selected volume of Emily Dickinson's poems(Amazon, 2021). It contains the best of Emily Dickinson's poetry - 576 poems that fully and fairly represent not only the complete range of Dickinson's poetic genius but also the complexity of her personality, the fluctuation of her mood, and the development of her style(Hachette Book Group, 2021). Christian Science Monitor reviewed it as the first truly selected poems of Emily Dickinson and is like a monument at the end of a very long road in literary history (Hachette Book Group, 2021). Kirkus Reviews mentioned that in Final Harvest, Thomas H. Johnson]has selected the best known and those which are particularly pertinent to her life and illustrate and illuminate some special quality (Final Harvest, 1961). Professor William Doreski (1946-) valued this anthology as a thoughtful and extensive selection from Johnson's 1955 variorum, and remains the best introduction to Dickinson's world (Doreski, 2016).

\section{LITERATURE REVIEW}

Though an important selection of Emily Dickinson's poetry, Final Harvest: Emily Dickinson's Poems has not aroused wide attention of Chinese academia and readers, as there were hardly any comments or reviews of Final Harvest in China in the past several decades.Furthermore, since the first and only Chinese translation, Final Harvest, translated by $\mathrm{Mu} \mathrm{Yu}$, was published by Flower City Publishing House in 1996 in Guangzhou, China, there has been only one comment on the translation. He Rongdong, based on brief discussion of translation of a few words and sentences, pointed out some translation problems, but not evaluating the whole translation (He, 2004). Zhang Shijun did mentioned the publication of Chinese translation of Final Harvest in his brief introduction of Emily Dikcinson's poems, yet made no comment on the translation (Zhang, 1997). Obviously, the Chinese translation of Final Harvest has not been analyzed and evaluated, and the importance of the anthology has not been recognized by Chinese academia and readers. This paper intends to reveal the translation features of the Chinese translation of Final Harvest, on the one hand, to showcase features of Chinese translation of Emily Dickinson's poem, and more importantly on the other hand, to remind Chinese academia and readers of the importance of the anthology and the urgency of retranslating it.

Using Antconc software and program written in python language to count and analyze relevant data of stanzas, lines, punctuation marks, transliterated words and conjunctions in the original and translation, this paper reveals translation features of the translation from three aspects, i.e. the translation of poetic form, logical relation, and application of foreignization translation method. From a total of 576 translated poems, 302 are randomly selected as research objects, which are poems 1-100, 288-388 and 476-576 (poem 576 is marked as 152-a in the book), for more than half of the total translated poems are sufficient to help reveal translation features of the translation. Each translated poem in $\mathrm{Mu} \mathrm{Yu}$ 's translation is marked with a poem serial number, which will be used accordingly in this paper. 


\section{TRANSLATION FEATURES OF FINAL HARVEST}

Data of poetic form, transliterated words, and conjunctions are collected and analyzed to discover translation features of the Chinese translation. Poetic form refers to such elements as stanza, line, and punctuation marks, while punctuation marks here include dash, comma, period, exclamation mark, question mark, colon, semicolon, and caesura sign.

\subsection{Poetic Form}

\subsubsection{Stanza and line}

The number of stanzas and lines of each original and translated poem are counted, and differences between the original and translation in terms of stanza and line are observed, as shown in Table $1 \& 2$.

Table 1. Statistics of Stanzas and Lines in the Original and Translation

\begin{tabular}{|l|l|l|l|l|}
\hline & Original & Translation & Difference Value & Difference Ratio \\
\hline Stanzas & 739 & 725 & 14 & $1.89 \%$ \\
\hline Lines & 3501 & 3501 & 0 & 0 \\
\hline
\end{tabular}

Table 2. Translations with Stanzas or Lines Deviation from the Original

\begin{tabular}{|l|c|c|}
\hline Translations & On Stanzas & On Lines \\
\hline Translations with less Stanzas or Lines & 15 & 0 \\
\hline Translations with More Stanzas or Lines & 1 & 0 \\
\hline Total and Percentage & $16(5.3 \%)$ & 0 \\
\hline
\end{tabular}

Statistics show that the number of translated lines is exactly the same as the original, and the number of translated stanzas is very little different from the original, accounting for only $1.89 \%$, which involves with only 16 translations, accounting for $5.30 \%$ of the total 302 poems. It can be seen that the translation is highly faithful to the original in terms of stanza and verse line.

\subsubsection{Stanza}

As shown in Table 1, there are 739 original stanzas and 725 stanzas in the translation of 302 poems, which is 14 stanzas less than the original, accounting for $1.89 \%$. The deviation of these 14 stanzas involves 16 translations (see Table, 2). Among them, 1 translation, i.e. translation of poem 514, has more stanzas than its original, the remaining 15 translations have fewer stanzas than the original, which are the translations of poems $4,14,24,26,28,50,66$, $77,83,89,325,327,355,375,564$. Moreover, all of the 16 translations have each only 1 stanza different from the original.

The difference between the original and translation in terms of stanza affects the accurate reproduction of original form and content, and affects readers' reading experience and understanding of poem. Poetry translation is different from prose translation in that its stanza segmentation, line breaks, sentence length and other formal factors may influence visual manifestation and expressive power of poetry. Chinese Scholar Gu Zhengkun (1952- ) once clearly put forward the concept of poetic formal vision, saying that poetic formal vision includes pictorial vision of word itself, formal vision of poetic sentence, and special vision produced by ingenious combination and separation of writing and arrangement of characters and words, all of which are important elements of poetry (Gu, 2003). Therefore, in poetry translation, stanza should be translated as faithfully as possible.

\subsubsection{Line}

Statistics show (see Table 1) that the total number of lines of original 302 poems is 3,501, which is the same as that in translation. However, it may be the result of increasing or decreasing the number of lines in specific translation. Therefore, the author of this paper also 
makes statistics on deviation of the number of lines between each translation and the original (see Table 2). The result shows that each of 302 translations has the same number of lines as its original.

\subsubsection{Summary}

$\mathrm{Mu}$ Yu's translation is exactly the same as the original in lines. The little difference in the number of stanzas between the original and translation accounts for only $1.89 \%$. Among the 16 translations involved, each of the 15 translations has one less stanza than the original, and 1 translation has one more stanza than the original. Poetic form(including stanza and line) is of great significance to poetry, and will directly affect readers' perception of pause, artistic conception and visual beauty of poetry. Therefore, deviation of poetic form from the original is not a practice worth recommending.

\subsubsection{Punctuation}

Part of special expressive power of poetry lies in skillful use of punctuation marks by the poet, especially so for those poems whose language is highly condensed and meaning is difficult to understand. Without the help of punctuation marks, it is often impossible to understand the complex syntactic relations, rhymes and even poetic meaning. The particularity and rhetoric function of punctuation in poetry is beyond the reach of prose and other functional genres (Guo, 1991). However, Chinese researcher Zhang Wanning pointed out that many translators pay much attention to the structure of sentences and the choice of words when translating from English to Chinese, but when they come to punctuation marks, they feel quite relieved (Zhang, 2004). Different punctuation marks may have different impact on expression of poetic meaning and poet's emotion. Misuse of punctuation marks will directly affect the quality of translation. Therefore, attention should be paid to translation of punctuation marks.

Statistics of 8 punctuation marks are conducted, and it is found that there is no colon used, neither in the original nor in translation. Table 3 shows the number of 7 punctuation marks used in 302 original and translated texts. Among them, caesura sign is unique in translation, as there are several places where original commas are converted into caesura signs in translation, and there are no caesura signs used in the original.

Table 3. Statistics of 7 Punctuation Marks in the Original and Translation

\begin{tabular}{|l|l|l|l|l|l|l|l|l|}
\hline Punctuation & Dashes & Commas & Periods & $\begin{array}{l}\text { Exclamation } \\
\text { Marks }\end{array}$ & $\begin{array}{l}\text { Question } \\
\text { Marks }\end{array}$ & $\begin{array}{l}\text { Semi- } \\
\text { Colon }\end{array}$ & $\begin{array}{l}\text { Caesura } \\
\text { Signs }\end{array}$ & Total \\
\hline Original & 2384 & 553 & 215 & 192 & 53 & 3 & 0 & 3400 \\
\hline Translation & 2376 & 541 & 213 & 192 & 54 & 3 & 5 & 3384 \\
\hline $\begin{array}{l}\text { Difference } \\
\text { Value }\end{array}$ & 8 & 12 & 2 & 0 & -1 & 0 & -5 & \begin{tabular}{l}
16 \\
\hline
\end{tabular} \\
\hline
\end{tabular}

Statistics show that (see Table 3 ) the total number of punctuation marks in translation is 16 less than that in the original, accounting for $0.47 \%$. There are 28 cases of punctuation deviation from the original, accounting for $0.82 \%$. Generally speaking, punctuation deviation in translation is not obvious.

Among the 7 types of punctuation in statistics, the quantity of deviation of each punctuation in translation is quite small. Specifically, there is no deviation of exclamation mark and semicolon; the number of deviation of period and question mark is 2 and 1 respectively; Of the 5 caesura signs in translation, 3 are the result of conversion from original commas ( in poem 16), and 2 are added by the translator ( in translation of poem 332); Deviation of dash and comma is comparatively large, in which the number of deviation reaches to 8 dashes (accounting for $0.34 \%$ ) and 12 commas (accounting for $2.17 \%$ ) respectively, yet the proportion is small. 
The fact that statistical data show no punctuation deviation in translation does not necessarily mean that the use of punctuation marks in translation is exactly the same as in the original . In fact, it may be the result caused by same number of punctuation marks addition and deletion in translation. Therefore, the actual situation needs to be verified by comparing punctuation marks of each original with that of the translation. After verification, it is found that neither the original nor the translation uses colons, and the use of semicolons in the original and the translation is the same (semicolons are used in poems 498, 567 and 574). Statistics of translations with punctuation deviation are shown in Table 4.

Table 4. Statistics of Translations with Punctuation Deviation

\begin{tabular}{|l|c|c|c|c|c|c|}
\hline $\begin{array}{l}\text { Deviated } \\
\text { Translations }\end{array}$ & $\begin{array}{c}\text { On } \\
\text { Dash }\end{array}$ & $\begin{array}{c}\text { On } \\
\text { Comma }\end{array}$ & $\begin{array}{c}\text { On } \\
\text { Period }\end{array}$ & $\begin{array}{c}\text { On Exclamation } \\
\text { Mark }\end{array}$ & $\begin{array}{c}\text { On Question } \\
\text { Mark }\end{array}$ & $\begin{array}{c}\text { On Caesura } \\
\text { Sign }\end{array}$ \\
\hline $\begin{array}{l}\text { Translations with } \\
\text { Less Punctuation }\end{array}$ & 8 & 15 & 4 & 1 & 0 & 0 \\
\hline $\begin{array}{l}\text { Translations with } \\
\text { More Punctuation }\end{array}$ & 6 & 4 & 2 & 1 & 1 & 2 \\
\hline Deviation Total & 14 & 19 & 6 & 2 & 1 & \\
\hline Deviation Ratio & $4.64 \%$ & $6.29 \%$ & $1.99 \%$ & $0.66 \%$ & $0.33 \%$ & $0.66 \%$ \\
\hline
\end{tabular}

Punctuation difference between an individual translation and its original results from two occasions, in which the number of punctuation marks in translation is either less or more than the original. Statistics show (see Table $3 \& 4$ ) that the total number of dashes in translation is 8 less than that in the original, with 14 translations involved. Among them, 8 translations have fewer dashes than the original, and 6 translations have more dashes than the original texts. Furthermore, difference in total number of commas between the translation and the original is 12, with 19 translations involved. Differences between the translation and the original in total number of periods, exclamation marks, question marks, and caesura signs are smaller, with less translations involved. Although dash and comma deviation is relatively more prominent than deviation of other punctuation marks, their deviation rate accounts for only $4.64 \%$ and $6.29 \%$ respectively. In a word, deviation of the translation from the original text is not obvious in terms of punctuation. Detailed analysis of deviation of the six punctuation marks listed in Table, 4 is as follows:

\subsubsection{Dash}

According to statistics (Tables $3 \& 4$ ), the total number of dashes in translation is 8 less than that in the original, with 14 translations involved. Among the 14 deviated translations, 8 have one less dash than the original. They are the translations of poems $31,37,41,80,89,307$, 329 , and 522; and 6 has one more dash than the original, which are the translations of poems $38,57,65,76,98$, and 314 .

In general, dash may facilitate restatement, sub-statement, modification, explanation and supplementary explanation, as well as leading to sudden transition in semantics. The usage of dashes in English and Chinese is basically the same, and their cohesive functions are similar. Therefore, in many cases, dash can be transplanted in translation (He, 2011). In addition, English dash is means of textual cohesion, functioning like "i.e." or "that is". Researcher Liang Li pointed out that when translating from Chinese to English, dash or colon can also be used to connect the antecedent and apposition in English to highlight the information center, i.e. apposition (Liang, 2001).

Of all the punctuation marks counted, dash is the most extensively used in Dickinson's poems. However, Dickinson's dashes, with their particularities, are different from ordinary dashes in that they have richer expression power, contributing to her unique style. Researcher Ji Hongxin pointed out that Dickinson's dashes, like the beat of music, help slowing down readers' reading speed and revealing the poet's emotion as well (Ji, 2013). More scholars have pointed out that among many functions dashes play in Dickinson's poems, the most important 
is its shaping of visual effect of the poem. Punctuation in Dickinson's manuscripts includes various oblique lines with various gradients, prolonged periods, arcs and stress symbols, etc., which often frustrated editors of her poems. In printed version, due to limitation of typesetting and printing regulations, original irregular slashes in Dickinson's manuscripts are treated and printed as short horizontal bar similar to dashes (Ji, 2013). Researchers Zuo Jinmei and Zhou Xinlei also pointed out that Dickinson is an iconic figure in visual poetics, in that dots, lines, and surfaces in her poetry together construct an explicit visual picture with aesthetic value. Although printed texts can hardly reproduce various slopes and lengths of diagonal lines in manuscripts, large number of dashes in printed version can also convey a certain degree of line aesthetics (Zuo, 2019).

Undoubtedly, extensive use of dashes with many of the aforementioned functions is one of the major features and an indispensable part of Dickinson's poetry. Therefore, translator should try to keep original dashes intact in translation. The 14 translations with dash deviation, though not accounting for a large proportion of the total of 302 translations, reflect a deviation from the original, which reduce the fidelity of punctuation translation to some extent. Dash addition or deletion will undoubtedly bring harm to fluency and visual picture of poetry, increases or decreases reader's experience of the original dashes, which is not conducive to reader's understanding of original poetic emotion.

\subsubsection{Comma}

The total number of commas in translation is 12 less than that in the original (see Table 3), involving 19 translations, of which 15 have fewer commas than the original, and 4 have more commas than the original(see Table 4). According to statistical results of Table 5, among the 15 translations with fewer commas than the original, 13 of them have 1 comma less than the original. They are translations of poems 4, 5, 9, 27, 49, 55, 78, 79, 89, 334, 510, 552, and $560 ; 1$ has 2 commas less than the original (i.e. translation of poem 21 ); 1 has 3 commas less than the original (i.e. translation of poem 16 ), and thus a total of 18 commas less than the original. Among the 4 translations that have more commas than the original, 3 have 1 comma more than the original, they are the translations of poems 386,553 , and 556; 1 has 3 commas more than the original (that is, translation of poem 51), totaling 6 commas more than the original. Therefore, there are a total of 24 cases of comma deviation in the 19 translations with comma deviation.

Table 5. Statistics of Translations with Comma Deviation

\begin{tabular}{|l|c|c|}
\hline Differences in Comma & No. of Deviated Translations & No. of Deviated Commas \\
\hline 1 less than the original & 13 & 13 \\
\hline less than the original & 1 & 2 \\
\hline 3 less than the original & 1 & 3 \\
\hline 1 more than the original & 3 & 3 \\
\hline 3 more than the original & 1 & 3 \\
\hline Total & 19 & 24 \\
\hline
\end{tabular}

The 24 cases of comma deviation from the original in 19 translations are the result of deletion and addition of comma in translation. There are two main types of deletions: conversion and omission. First, the original comma is converted into other punctuation marks, such as into period ( e.g. in poem 9), question mark (e.g. in poem 27), and caesura sign (e.g. in poem 16). Since period, question mark and comma each has their own unique function, converting an original comma into a period or a question mark in translation may bring a different effect to the translation, while converting a comma into a caesura sign in translation may also make the translation missing something from the original. Second, omit original comma in or at the end of the original line, such as in translations of poem $4,5,49,21$, and 
334. The omission of original comma also makes readers' reading experience different from reading of the original.

As for addition of commas in translation, there are two kinds: conversion of other punctuation marks into commas and direct addition of commas. For the first, there are two cases in which the number of commas increases by conversion of an original period into a comma, i.e. in translations of poems 386 and 553. Since period has its special concluding function, it is unreasonable to change the fluency and context of the original text by converting original period into comma in translation. For the second, there is direct addition of a comma in a line (e.g. in translation of poem 51) or at the end of a line (e.g. in translation of poem 556) .

In short, in terms of comma, there are not many translations that deviate from the original, and the number of deviated commas is not large, but these deviations all affect fidelity of the translation to the original in varying degrees.

\subsubsection{Period}

The number of periods in $\mathrm{Mu}$ Yu's translation is 2 less than that in the original (see Table 3 ). In fact, there are 4 cases of deletion and 2 cases of addition (see Table 4). There are 6 changes in total, involving 6 translations. One original period is deleted in each of the four translations, i.e. translations of poems 386, 520, 553 and 555), and a period is added to each of the two translations, i.e. translations of poems 2 and No. 9. The increase or decrease of period in translation results from conversion or omission.

Conversion includes converting original period into a comma (such as in translations of poems 386 and 553), or original exclamation mark into a period (such as in translations of poems 2) or a comma into a period (such as in translations of poems 9); omission translation is to omit original period in translation (such as in translations of poems 520 and 555). The increase or decrease of period in translation distorts the original text to a certain extent.

\subsubsection{Exclamation mark}

Similar to dash, exclamation mark, which is similar to vertical line, also has a rich visual expression effect. "While Dickinson's earliest poetry was conventionally punctuated, by 1858 she is consistently using highly individualized punctuation to create an intensity of tone in her poems. The overuse of the exclamation mark is the most pronounced punctuation feature of this period and occurs in letters as well as in poems" (Denman, 1993, p. 31). Translator should be faithful to the original when translating exclamation mark. Although there is no deviation in the number of exclamation marks between the original and translation, however, after checking each one of original and translated exclamation marks, it is found that in translation there is an exclamation mark added (i.e. in translation of poem 2), and an exclamation mark deducted (i.e. in translation of poem 76), which leads to the zero deviation in total number of exclamation marks between the translation and the original. Exclamation mark generally has strong emotional implications and prominent visual impact. Adding or subtracting exclamation marks in translation will produce effects that are inconsistent with the original in terms of emotional expression and visual communication.

\subsubsection{Question mark}

Among the 302 poems counted, the number of question marks in translation is one more than that in the original (see Table 3). Only in translation of poem 27 that an original comma is converted into a question mark, while question marks in the remaining translations are faithful to the original. The original lines of poem 27 "Next time, to tarry, / While the Ages steal - / Slow tramp the Centuries, / And the Cycles wheel!" is translated as “下一次，逗留， / 任光阴流逝一一/ 漫步度悠久? / 轮回但无已! ” , the comma at the end of the original third line was translated into a question mark. However, there is no rhetorical tone in original text. The added question mark changed the tone and meaning of the original poem.

\subsubsection{Caesura sign}


Five caesura signs are added in $\mathrm{Mu}$ Yu's translation. Among them, in translation of poem 16, 3 parallel commas in the original are converted into caesura signs (i.e. “、”), which maintains original juxtaposition effect while at the meantime weakens the more distinct sense of pause in original text to a certain extent. And in translation of poem 332, 2 caesura signs are added to places where the original text is without punctuation, which reduces the original fluency provided by original conjunction "and" .

\subsubsection{Summary}

Punctuation in $\mathrm{Mu}$ Yu's translation does not deviate significantly from the original. Among the 8 punctuation marks counted, there is no colon used in the original and translation, and the number and use of semicolon in both translation and the original are exactly the same, while the remaining 6 punctuation marks are slightly different from the original in terms of total number as a whole or in the number of translations involved. Among them, deviation of dash and comma is comparatively large, but the proportion is small. The difference in punctuation between the original and translation is mainly caused by means of addition, omission, and conversion.

However, no matter what method is adopted to make translation deviated from the original in terms of punctuation, any changes of original punctuation will affect fidelity of translation to the original in varying degrees, such as distorting, weakening, or deleting original fluency, pause, contextual connection, transition, conclusion, parallel relationship, meaning or tone extension or emphasis, emotional expression, etc. Therefore, translation of punctuation should be as faithful to the original as possible.

\subsection{Transliterated Word}

Lawrence Venuti, a well-known American translation theorist, put forward the translation terms Domestication and Foreignization in his 1995 book The Translator's Invisibility--A History of Translation. Roughly speaking, domestication method is to bring original author into target language culture, while foreignization method is to accept language and cultural differences of foreign language text, and bring reader into a foreign situation (Venuti, 1995). The purpose of domestication translation is to make content and expression of translation look close to reader's native language, and minimize or hide differences between cultures. Translator can use free translation at appropriate time to promote readers' understanding of the work, so that readers can better understand foreign culture of the original text; translator can also use foreignization translation method to deliberately break linguistic habits of target language and retain foreign language and cultural characteristics in translation, so that readers can clearly feel foreignness of the translated language (Xu, 2002).

There are many examples of foreignization translation in $\mathrm{Mu}$ Yu's translation. One of the highlights is that there are a large number of transliterated words in translation, with some transliterated words accompanied by explanatory footnotes, while many others not provided with explanatory footnotes. Transliterated words with footnotes can be called footnoted transliterated words. In 302 translations, there are 68 transliterated words and 34 footnotes, of which 22 footnotes are notes on transliterated words. In other word, there are 22 footnoted transliterated words, 3 of which are place names: 塞萨利(Thessaly, poem 292), 海布拉(Hybla, poem 292), and 伯利恒(Bethlehem, poem 516); 2 refer to wine: 霍克(Hock, poem 52) and 迪 姆 - 勃艮地(Dim Burgundy, poem 52); 1 is cheering word to God: 哈利路亚(Hallelujah, poem 1); and 1 is a unit of measurement: 里格(league, poem 30), but the most numerous is the 15 names of people, gods and animals, as shown in Table 6:

Table 6. 15 Transliterated Words for Names of People, Gods and Animals 


\begin{tabular}{|l|l|l|l|}
\hline No. & \multicolumn{3}{|c|}{ Transliterated Words and the Originals } \\
\hline 1 & $\begin{array}{l}\text { 阿尔班 } \\
\text { (Alban, poem 22) }\end{array}$ & $\begin{array}{l}\text { 布里更 } \\
\text { (Brigand,poem 26) }\end{array}$ & $\begin{array}{l}\text { 加百利 } \\
\text { (Gabriel,poem 38) }\end{array}$ \\
\hline 2 & $\begin{array}{l}\text { 布赖恩特 } \\
\text { (Bryant,poem 24) }\end{array}$ & 彼得(Peter,poem 37) & $\begin{array}{l}\text { 墨丘利 } \\
\text { (Mercury,poem 344) }\end{array}$ \\
\hline 3 & $\begin{array}{l}\text { 汤姆森 } \\
\text { (Thomson, poem 24) }\end{array}$ & $\begin{array}{l}\text { 赫歇耳 } \\
\text { (Herschel,poem 344) }\end{array}$ & $\begin{array}{l}\text { 伊阿宋 } \\
\text { (Jason (Easun) poem 510) }\end{array}$ \\
\hline 4 & $\begin{array}{l}\text { 门农 } \\
\text { (Memnon,poem 68) }\end{array}$ & $\begin{array}{l}\text { 切尔克斯人 } \\
\text { (Circassian,poem 383) }\end{array}$ & $\begin{array}{l}\text { 俄耳甫斯 } \\
\text { (Orpheus,poem 525) }\end{array}$ \\
\hline 5 & $\begin{array}{l}\text { 尼科迪默斯 } \\
\text { (Nicodemus,poem 25) }\end{array}$ & $\begin{array}{l}\text { 德摩斯梯尼 } \\
\text { (Demosthenes,poem 493) }\end{array}$ & $\begin{array}{l}\text { 达拉膜 } \\
\text { (Durham,poem 524) }\end{array}$ \\
\hline
\end{tabular}

The 22 footnoted transliterated words translated by foreignization method retain exotic flavor of their original words, and with footnotes provided, they are easily understood and accepted by Chinese readers.

However, there are 46 transliterated words which are without footnotes in the translation, accounting for two-thirds. Some examples are: 基德(Kidd, poem 2), 几尼(guinea, poem 5), 雅 各(Jacob, poem 9), 辛马勒(Himmaleh, poem 61), 萨克逊 (Saxon, poem 75), 奥甘迪（ Organdy, poem 76), 戈尔康达 (Golconda, poem 92), 辛玛勃(Himmaleh, poem 352), and 多明各(Domingo, poem 355), etc. Different from 伊甸园(Eden, poem 44), 莱茵河(Rhine, poem 46), 博斯普尔斯海峡(Bosporus, poem 293) and other transliterated words that are relatively familiar to Chinese readers, most of these transliterated words without footnotes are likely to be incomprehensible and make Chinese readers confused, and become obstacles for readers to understand the poems. These transliterated words without explanatory footnotes may reduce readability of translation and affect faithfulness of translation to the original in terms of content.

\subsection{Conjunction}

Statistics of conjunctions in 302 original poems and their translations are shown in Table 7:

Table 7. Statistics of Conjunctions in the Original and Translation

\begin{tabular}{|l|l|l|l|l|l|}
\hline & \multicolumn{2}{|c|}{ Original } & \multicolumn{2}{c|}{ Translation } & \\
\hline No. & $\begin{array}{l}\text { Freq } \\
\text { uenc } \\
\text { y }\end{array}$ & Conjunctions & $\begin{array}{l}\text { Freque } \\
\text { ncy }\end{array}$ & Conjunctions & $\begin{array}{l}\text { Differe } \\
\text { nce } \\
\text { Value }\end{array}$ \\
\hline 1 & 14 & because/due to/since & 26 & 因为/由于 & 12 \\
\hline 2 & 27 & so /therefore/hence/thus & 11 & 所以/因此/于是/故 & 16 \\
\hline 3 & 13 & $\begin{array}{l}\text { although/though/even though } \\
\text { /even if }\end{array}$ & 15 & 尽管/即使 & \\
\hline 4 & 15 & Still & 18 & 仍然/依旧/依然/仍旧 & 3 \\
\hline 5 & 139 & but/however/while & 126 & 但/却/而/然而 & 13 \\
\hline
\end{tabular}




\begin{tabular}{|l|l|l|l|l|l|}
\hline 6 & 406 & And & 130 & 和/与 & 276 \\
\hline 7 & 49 & Then & 14 & 然后/之后/随后 & 35 \\
\hline 8 & 75 & Or & 55 & 或/或者/或是 & 20 \\
\hline 9 & 56 & If & 68 & 如果/假如/若/假若/倘若 & 12 \\
\hline Total & 794 & & 463 & & 331 \\
\hline
\end{tabular}

It can be seen from statistics that the degree of correspondence between the translation and the original in terms of conjunction is not high. The number of conjunctions that express causality, transition, concession, hypothesis, succession and conditions in the original and translation are quite different, and there is greater difference in number between original conjunction “and" and its Chinese equivalent conjunction “和”. On the whole, the total number of nine types of translated conjunctions counted is significantly less than that of the original, with a deviation value of 331 , accounting for $41.69 \%$, and, there are a total of 389 cases of deviation in translation of conjunctions.

Due to diversity and complexity of logical expression in English and Chinese language, conjunctions are not the only means to connect and reflect logical relation between components in English and Chinese. Only counting the differences in the use of conjunctions, large or small, can not cover all the differences in logical relation between the original and translation, but it can still reveal the discrepancy between the original and translation to some degree. This paper mainly analyzes most commonly used and basic logical conjunctions in English and Chinese, namely, five types of conjunctions that express causality, concession, transition, juxtaposition and hypothesis, and generally examine the fit of the translation to the original logical relation.

First, conjunctions of causality in translation are not highly corresponding to the original. The number of translated conjunctions expressing reason (e.g. 因为, equivalent to "because"/ "due to"/ "since") is 12 more than that of the original, but the number of translated conjunctions expressing consequence (e.g 所以, equivalent to "so"/ "therefore"/ "hence"/ "thus") is 16 less than that in the original (see Table 7), which shows that translator has selectively increased or decreased the number of conjunctions in translation in dealing with the causal logic of the original text, such as adjusting the original sentences expressing consequence to translated sentences expressing reason.

Second, in terms of conjunction representing concession relation (i.e. "still"), the translation and the original correspond to a high degree, and the deviation value is only 3 . Third, in terms of conjunctions that express transition relation (i.e. "but"/ "however"/ "while"), the translation differs greatly from the original. 13 of original transitional conjunctions are not translated, which may cause readers' confusion in understanding the text. The transition relation plays an important role for readers in analyzing the context and understanding the meaning of poetry.

Fourth, there is huge difference between the translation and the original in terms of conjunction expressing juxtaposition (i.e. "and"). According to statistics (see Table 7), 276 original conjunctions expressing juxtaposition are omitted in translation. However, the huge difference here is understandable, because "and" in English usually has no actual meaning, and only serves as a connection or succession between sentences or words. Sometimes there is no need to translate it in translation, but too many omissions will become a problem. In addition, the omission of 35 original "then" in translation is questionable. Compared with "and", the succession meaning of "then" is more obvious and has practical meaning, so it should be 
translated as much as possible in translation. Of course, to use addition or omission when translating, it depends on specific situation in individual text. However, since 35 of a total of 49 original "then" have been omitted in translation, accounting for $71.42 \%$, it can be said that this is too much omission and will affect reproduction of artistic conception of the original poem. From the perspective of faithfulness in poetry translation, it is not appropriate to omit such words or elements which express obvious logical relation.

Fifth, there is also deviation in conjunction expressing hypothesis (i.e. "if"), with a deviation value of 12 . Since hypothetical conjunctions have extremely obvious hypothetical function, adding or deleting them will directly change meaning and logic of sentence, so any changes to such conjunctions in translation should be minimized as far as possible.

In short, the number of conjunctions used in $\mathrm{Mu}$ Yu's translation is not close to that of the original. Since logical relation contained in conjunctions may directly affect poetic expression, a large number of additions, deletions or changes to original conjunctions in translation will distort meaning of original poems, preventing readers from fully understanding original meaning, and affecting fidelity of translation to the original in content.

\section{CONCLUSION}

Using Antconc software and program written in Python language to conduct statistical survey and analysis of the number of stanzas and lines, punctuation marks, transliterated words and conjunctions in the original and $\mathrm{Mu}$ Yu's translation, translation features of $\mathrm{Mu} \mathrm{Yu}^{\mathrm{\prime}} \mathrm{s}$ translation are revealed from three aspects, i.e. the translation of poetic form, logical relation, and application of foreignization translation method.

First of all, Mu Yu's translation is relatively loyal to the original in terms of stanza and line. The number of lines is exactly the same as the original, and the number of stanzas is 14 fewer than the original, accounting for only $1.89 \%$, with 16 translations involved.

Second, punctuation in $\mathrm{Mu}$ Yu's translation does not deviate significantly from the original. Among the 8 punctuation marks counted, colon is not used in the original nor the translation, and semicolon has no deviation from the original. The number and use of the remaining 6 punctuation marks are only slightly different from the original. Among them, deviation of dash and comma are comparatively prominent, but quantity of deviation cases account for only a very small proportion.

Third, there are many transliterated words in translation without explanatory footnotes. According to statistics of the 302 translations, there are 68 transliterated words, of which only 22 transliterated words are accompanied by footnotes. There are still many non-footnoted transliterated words that are unfamiliar to Chinese readers and will be difficult for readers to understand their meaning, which will reduce readability of the translation, hinder transmission of original meaning and is not conducive to communication and exchange of different cultures.

Fourth, the translation has a significant deviation from the original in terms of logical relation. The number of conjunctions in translation does not highly correspond to the original. Among 302 poems counted, the number of translated conjunctions is 331 (41.69\%) less than that of the original, and the number of deviation cases reaches 389 , which is a big difference. Conjunctions reflect logical relation of text, and are closely related to meaning expression and readability of the text. Excessive conversion or omission of original conjunctions in translation will not only distort meaning of the source text, but also cause confusion for readers to understand the translated text.

In short, $\mathrm{Mu}$ Yu's translation is quite faithful to the original in terms of poetic form, such as in stanza, line, and punctuation. However, in translation of vocabulary, especially loanwords, as well as translation of logical relation, especially translation of conjunctions, the deviation from the original is very prominent. The faithfulness of $\mathrm{Mu} \mathrm{Yu}$ 's translation to the original is mainly manifested in poetic form rather than in content. 


\section{Acknowledgements}

This research is supported by 2015 Guangzhou Philosophy and Social Science Development Project of "the 12th Five-Year Plan":"A Study of Characteristics of Emily Dickinson's Poems Translation."(Project No.: 15Y10).

\section{REFERENCES}

Amazaon.(2021). Final Harvest: Emily Dickinson's Poems. https://www.amazon.in/FinalHarvest-Poems-Emily-Dickinson/dp/0316184152. Accessed 16 May 2021.

Anthony, L. (2021). AntConc (Version 3.5.8) [Computer Software]. Tokyo, Japan: Waseda University. Available from https://www.laurenceanthony.net/software.Accessed 16 May 2021.

Dickinson, E. (1955). The Poems of Emily Dickinson: Including Variant Readings Critically Compared with All Known Manuscripts, ed. Thomas H. Johnson. 3 vols. Cambridge, MA: Belknap Press of Harvard Univ. Press.

Dickinson, E. (1961). Final Harvest: Emily Dickinson's Poems, ed. Thomas H. Johnson. Boston, MA: Little, Brown and Company.

Denman, K.(1993). Emily Dickinson's Volcanic Punctuation. The Emily Dickinson Journal, 2 (1), 22-46.

Doreski, W.(2016) “The Auction of the Mind: Editing Emily Dickinson." Harvard Review Online. December 8, 2016. https://harvardreview.org/content/the-auction-of-the-mindediting-emily-dickinson/. Accessed 16 May 2021.

Feng, Y. (2018). Centenary Footprints Through Poetry: on Translating and Reading Emily Dickinson's Poems. Journal of Ningxia University (Humanities \& Social Sciences Edition), 40 (4), 66-70.

Final Harvest: Emily Dickinson's Poems. Kirkus Reviews. Issue: Jan. 1, 1961. https://www.kirkusreviews.com/book-reviews/a/thomas-h-johnson/final-harvestemily-dickinsons-poems/. Accessed 16 May 2021.

$\mathrm{Gu}$, Zh.-K. (2003). China and West: Comparative Poetics and Translatology. Beijing: Tsinghua University Press, .

Guo, T.-X. (1991). Rhetorical Function of Punctuation in Modern Russian Poetry. Foreign Language Education, (3), 71-75, 86.

Hachette Book Group.(2021). Final Harvest: Emily Dickinson's Poems. https://www.hachettebookgroup.com/titles/thomas-h-johnson/finalharvest/9780316184151/. Accessed 16 May 2021.

He, G.-H., Hu Sh.-G. \& Long L.-L. (2011). A Contrastive Study of Cohesive Function of English and Chinese Punctuation and Their Translation Techniques--Take Comma and Dash for Example. Journal of Shaoyang University (Social Science Edition), 10 (6), 82-84.

He, R.-D. (2004). On Translation of Dickinson's Poems from Chinese Version of Final Harvest. Journal of Leshan Normal University, (1), 54-57. 
Ji, H.-X. (2013). On the Use of Dashes in Emily Dickinson's Poems. Journal of Jiangsu Ocean University(Humanities \& Social Sciences Edition), 11 (18), 71-73.

Li, L. \& Ge G. (2018). View of Love in Emily Dickinson's Poems from the Perspective of Conceptual Metaphor: Take 'I Could not Stop for Death' for Example. Journal of Language and Literature Studies, 38 (4), 60-65.

Liang, L. \& Wang Zh. (2001). The Cohesive Function of Punctuation and the Information Processing in English-Chinese Translation.” Chinese Translators Journal, (4), 26-29.

Liu, X.-M. (2010). Comparison of Translation Styles between Two Chinese Versions of Emily Dickinson's Poems. Journal of Language and Literature Studies, (10), 91-93, 99.

Mu, Y. trans. (1996). Final Harvest: Selected Poems of Emily Dickinson. Guangzhou: Flower City Publishing House.

Nida, E. A. \& Charles R. T.(1969). The Theory and Practice of Translation. Leiden: E. J. Brill. Venuti, L. (1995). The Translator's Invisibility - A History of Translation. London: Routledge.

Xu, J.-P. \& Zhang R.-X. (2002). Foreignization and Domestication: an Examination from the Perspective of Cross-cultural Translation. Chinese Translators Journal, 23 (5), 38-41.

Yao, J. (2009). God of Death in the Sense of Beauty: An Analysis of 'Because I Could not Stop for Death'. Journal of Hefei University of Technology (Social Sciences), (4), 106-110.

Zhang, Sh.-J. (1997). Final Harvest. View on Publishing, (4):54.

Zhang, W.-N. (2004). On Flexibility of Punctuation Marks in Translation: Discussion with Mr. Chen Guangxiang. Shanghai Journal of Translators, (1), 52-53.

Zhou, J.-X. (2021). Chinese Translation of Emily Dickinson's Poetry: Translation Features of Shi Li's Lilacs in the Sky. International Journal of Language and Literary Studies, 3 (1) :177-192.

Zuo J.-M. \& Zhou X.-L. (2019). Visual Aesthetics in Emily Dickinson's Poems. Shandong Foreign Language Teaching, 40 (3), 78-89.

\section{$\underline{\text { AUTHOR'S BIO }}$}

Jianxin Zhou, Ph.D. is a professor of School of Foreign Languages, South China University of Technology, China, and is currently working at Lancaster University, UK. He is a writer, translator and researcher whose research interests include AngloAmerican poetry, comparison and translation of English and Chinese poetry, and pedagogy. Studying and translating Emily Dickinson's poetry is one of his enduring passions, and has produced fruitful research results in the past 30 years. 